\title{
Evaluation of mechanical properties of porous alumina ceramics obtained using rice husk as a porogenic agent
}

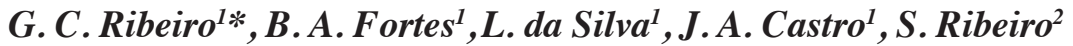 \\ ${ }^{I}$ Federal Fluminense University, Graduating Program in Metallurgical Engineering, Industrial Metallurgical \\ School of Volta Redonda, Av. dos Trabalhadores 420, 27255-125, Volta Redonda, RJ, Brazil \\ ${ }^{2}$ University of São Paulo, Department of Materials Engineering, 12600-970, Lorena, SP, Brazil
}

\begin{abstract}
The objective of this work was to evaluate the mechanical properties of porous alumina ceramics, using the rice husk as a porogenic element. The rice husk was milled and graded in two granulometry, $<65 \mu \mathrm{m}$ and $65-150 \mu \mathrm{m}$, and added in a high purity calcined alumina in the proportion of 5, 15 and $30 \mathrm{wt} \%$. The samples were pressed by uniaxial pressing and sintered at $1450{ }^{\circ} \mathrm{C}$ for $1 \mathrm{~h}$. Sintered density, total porosity, Young's modulus, modulus of rupture, and compressive strength were evaluated. Samples were also prepared without the addition of rice husk $(\mathrm{RH})$ in order to compare the properties. Porous ceramics with total porosity ranging from $24 \%$ to $54 \%$ were produced, and with the composition of 5\% RH 65-150 $\mu \mathrm{m}$, a high porosity value was obtained for a lower loss in mechanical properties.
\end{abstract}

Keywords: mechanical properties, porous ceramic, alumina, rice husk, porogenic agent.

\section{INTRODUCTION}

The interest in the development and optimization of porous ceramics is due to the wide field of technology in which those materials are applied, for example, catalysts, furnace linings, furnace furniture, filters for the automotive industry, glass production and acoustic insulation [1]. Porous ceramics can be produced by mixing porogenic agents in the ceramic matrix, which, during sintering, burn out forming the pores [2]. Some examples of materials used as porogenic elements are starches, polymers, wood and polymer foams [3-5]. Fig. 1 shows a schematic of the production of these porous ceramics. The porosity of ceramics is a result of the processing route of these materials by powder technology, resulting in an involuntary residual pore fraction. This fraction of residual pores is due to the limitation of the densification process that occurs during sintering. The production of porous ceramic materials can be purposeful, especially when they are used for applications such as filters and catalytic supports [6]. Residual porosity in ceramics results in a reduction in the mechanical strength of the final product. Thus, porous ceramics generally have lower mechanical resistance when compared to dense ceramics. Therefore, their applications are different and can not be used as structural materials $[7,8]$. The main properties of porous ceramics are low thermal conductivity, low density, high surface area, high permeability and high refractoriness [9].

The rice husk (RH) has in its composition a fraction of organic matter that can be used as a porogenic element $[2,10$, 11]. In addition, the $\mathrm{RH}$ has a large amount of silica $\left(\mathrm{SiO}_{2}\right)$, with $20 \%$ of inorganic matter present in the husk, about $95 \%$

*girribeiro@yahoo.com.br

(D) https://orcid.org/0000-0003-1291-5980

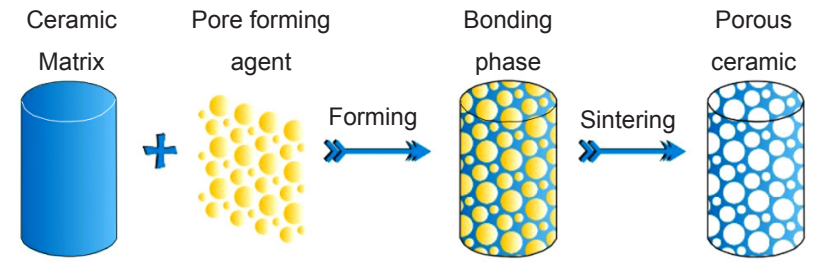

Figure 1: Schematic of the pore-forming agent method for porous ceramic production.

of silica, which can react with alumina at high temperatures to generate mullite $\left(3 \mathrm{Al}_{2} \mathrm{O}_{3} .2 \mathrm{SiO}_{2}\right)$, according to Eq. A [1215]. The formation of this crystalline phase contributes to the improvement of the thermal and mechanical properties of the ceramic produced $[2,16]$.

$$
3 \mathrm{Al}_{2} \mathrm{O}_{3}+2 \mathrm{SiO}_{2} \stackrel{\geq 1300^{\circ} \mathrm{C}}{\longrightarrow} 3 \mathrm{Al}_{2} \mathrm{O}_{3} \cdot 2 \mathrm{SiO}_{2}
$$

From the mixture of ground RH with high purity alumina, it is possible that during the sintering of the ceramic bodies, mullite can be generated, in addition to the formation of the pores due to the burning of the organic matter present in the RH. Mullite presents excellent properties, such as high refractoriness, high modulus of rupture, good resistance to thermal shock and chemical attack $[12,17]$. Due to these properties, this ceramic has great technological importance and is frequently used in refractory ceramics [17]. The incorporation of RH in natura or as ash is an alternative to reduce the environmental impact of the inadequate disposal of this agricultural residue in the environment [12]. In this study, the RH was used as a source of silica. The objective of this work was to study the influence of the addition of certain quantities and particles sizes of ground rice husk on 
alumina ceramics. It is intended to evaluate the crystalline phases, porosity, mechanical properties and microstructure of the obtained porous ceramics.

\section{MATERIALS AND METHODS}

The samples were obtained using high purity alumina powder manufactured by Baikalox with a particle size of $0.5 \mu \mathrm{m}$ and in natura $\mathrm{RH}$ provided by COOPAVALPA (Cooperative of the Rice Producers of Paraíba Valley). The rice husk was washed with tap water and then with distilled water to remove all impurities adhering to the husk surface and dried at $120{ }^{\circ} \mathrm{C}$ until constant weight. The $\mathrm{RH}$ was ground in an alumina ball mill for $2 \mathrm{~h}$ and then separated into two granulometric ranges: $<65 \mu \mathrm{m}$ and $65-150 \mu \mathrm{m}$. Mixtures of alumina with different percentages of RH were prepared in the proportions of 5, 15 and $30 \mathrm{wt} \%$. The mixing of the powders was performed manually with the aid of a glass stick until complete homogenization. Fig. 2 shows the flowchart of the experimental procedure.

The mixtures were pressed uniaxially in three different shapes, one for each specific analysis, as shown in Fig. 3, using a hydraulic press at $40 \mathrm{MPa}$. The processing of ceramics occurred without the use of binding agents, since there was no difficulty in pressing these mixtures. After pressing, the samples were fired for $1 \mathrm{~h}$ at $200,300,500$ and $1450{ }^{\circ} \mathrm{C}$. These firing levels were based on the thermogravimetric analysis of the rice husk [2,5] and also on preliminary tests, since the burning of the organic matter of the rice husk happens gradually until $200{ }^{\circ} \mathrm{C}$ and then more slowly until approximately $500^{\circ} \mathrm{C}$. The sintering temperature of $1450{ }^{\circ} \mathrm{C}$ was based on the phase diagram $\mathrm{Al}_{2} \mathrm{O}_{3}-\mathrm{SiO}_{2}$ [2]. The heating and cooling rates were 3 and $5{ }^{\circ} \mathrm{C} / \mathrm{min}$, respectively.

The porosity was determined by the mercury porosimetry using a porosimeter (Quantachrome, Poremaster) and the cylindrical samples, two of each composition, with $10 \mathrm{~mm}$ of diameter and $5 \mathrm{~mm}$ of height. Cylindrical samples, ten of each composition, with $16 \mathrm{~mm}$ of diameter and $14 \mathrm{~mm}$ of height, were subjected to the compression test in an EMIC testing machine according to ASTM C133 standard using a load cell of $100 \mathrm{kN}$ and actuator speed of $0.5 \mathrm{~mm} / \mathrm{min}$ [18]. The rectangular samples were machined in a Ferdimat machine with a diamond grinding wheel (D126) and then glued to metal plates. After that, they were cut with a $1.5 \mathrm{~mm}$ thick diamond wafer blade, obtaining prismatic samples with dimensions of approximately $42 \times 6 \times 3 \mathrm{~mm}$. The Young's modulus of these samples, ten of each composition, was determined by a non-destructive technique using the Sonelastic 3.0 equipment (ATCP Phys. Eng.). After

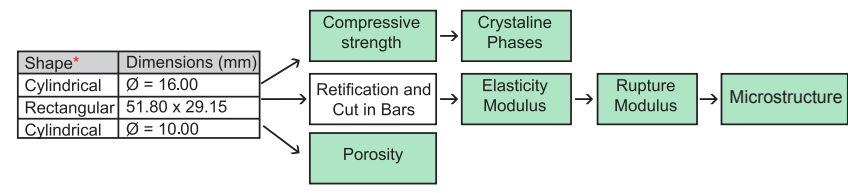

Figure 3: Shape of samples used in each analysis.

this analysis, the ten samples were submitted to a 3-point flexural test to determine their modulus of rupture. This test was performed in a universal mechanical testing machine (Shimadzu, Autograph AG-X) using a load cell of $5 \mathrm{kN}$ and loading speed of $0.5 \mathrm{~mm} / \mathrm{min}$. The modulus of rupture (MPa) was determined by:

$$
\sigma_{\mathrm{r}}=\frac{3 \mathrm{PL}}{2 \mathrm{Bw} w^{2}} \cdot \frac{\frac{\mathrm{L}}{2}-\mathrm{x}}{\frac{\mathrm{L}}{2}}
$$

where $\mathrm{P}$ is the force applied at the moment of fracture $(\mathrm{N})$, $\mathrm{L}$ the distance between the two lower supports $(\mathrm{mm})$, B the width of the specimen $(\mathrm{mm})$, w the height of the sample $(\mathrm{mm})$, and $\mathrm{x}$ a correction factor (distance between the position where the fracture occurred and the center of the sample $(\mathrm{mm})[19,20]$. For microstructural analysis of the fracture surface, a Hitachi TM3000 scanning electron microscope was used. The crystalline phases were identified by X-ray diffraction in a diffractometer (Panalytical, Empyrean) with monochromatic $\mathrm{CuK} \alpha$ radiation, angular range of $10^{\circ}$ to $80^{\circ}$ and step of $0.02 \%$.

\section{RESULTS AND DISCUSSION}

From the processing of porous alumina ceramics using ground rice husk (RH), it was possible to obtain green samples of all compositions with good resistance and without defects. However, the samples of compositions with $15 \%$ and $30 \%$ of RH $65-150 \mu \mathrm{m}$ did not withstand the firing process and the samples with addition of $30 \% \mathrm{RH}<65 \mu \mathrm{m}$ did not withstand the cutting stage. Therefore, the results of the compositions $5 \% \mathrm{RH}<65 \mu \mathrm{m}, 15 \% \mathrm{RH}<65 \mu \mathrm{m}$, and $5 \% \mathrm{RH} 65-150 \mu \mathrm{m}$ is discussed, compared to the results of the pure alumina composition. Fig. 4 shows the crystalline phase analysis of the four compositions with the addition of rice husk and the pure alumina composition. Peaks were identified using X'pert High Score software and indexed by JCPDS files: 15-0776 (mullite); 75-1862 ( $\alpha$-alumina); and 89-3435 (cristobalite). The X-ray diffractograms showed that the silica from rice husk reacted with alumina generating mullite. Peaks of mullite were observed as the amount of

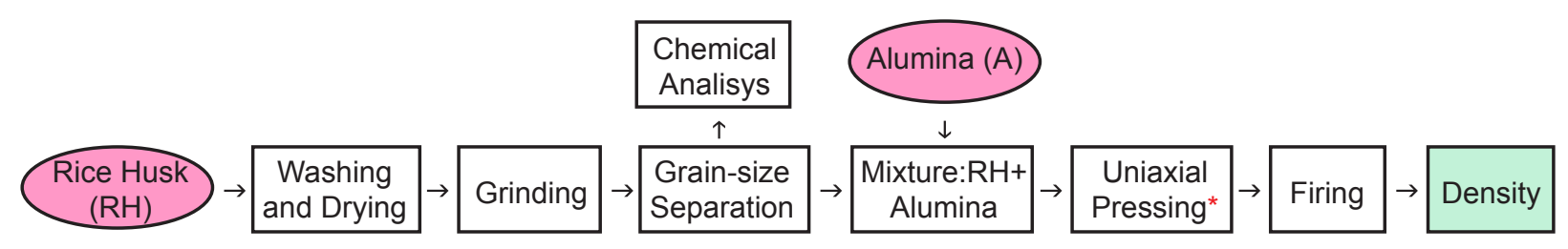

Figure 2: Flowchart of the experimental procedure. 


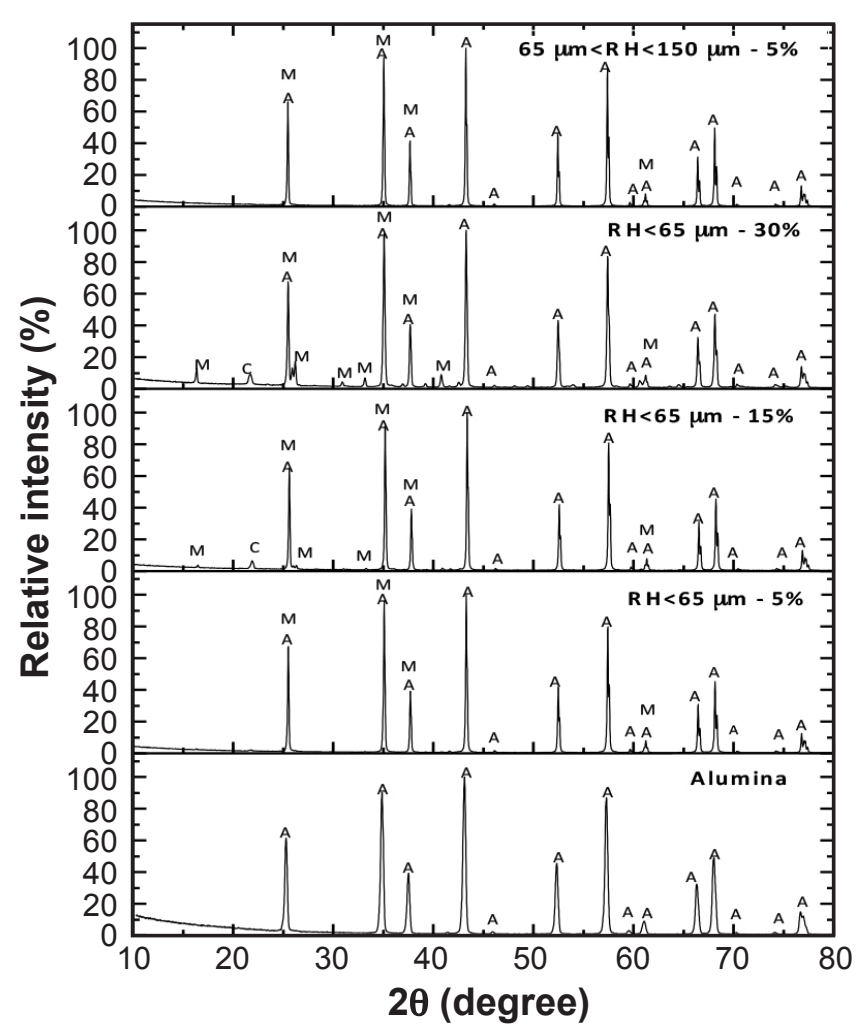

Figure 4: X-ray diffractograms of the compositions with rice husk addition and pure alumina composition sintered at $1450{ }^{\circ} \mathrm{C}$ for $1 \mathrm{~h}$ : A - $\alpha$-alumina, $\mathrm{C}$ - cristobalite, $\mathrm{M}$ - mullite.

rice husk increased. The higher the amount of rice husk used in the production of ceramics, the higher the concentration of silica after burning of the rice husk. Production of mullite is related to the amount of silica, so for larger proportions of rice husk used, a higher proportion of mullite phase was obtained. The presence of cristobalite in the compositions of $\mathrm{RH}<65 \mu \mathrm{m}$ with $15 \%$ and $30 \%$ of rice husk indicated that there was not sufficient time and temperature for all silica $\left(\mathrm{SiO}_{2}\right)$ to react with alumina $\left(\mathrm{Al}_{2} \mathrm{O}_{3}\right)$ to generate mullite $\left(3 \mathrm{Al}_{2} \mathrm{O}_{3} \cdot 2 \mathrm{SiO}_{2}\right)$. If the sintering time was longer, the cristobalite peak would not appear, because the silica would be consumed in the mulitization reaction (Eq. A).

Fig. 5 shows porosity and compressive strength variations according to the particle size of the rice husk powder and proportions used in the preparation of the samples. Among all cases, the highest total porosity obtained was $53.9 \%$ for the composition $\mathrm{RH}<65 \mu \mathrm{m}$ with $30 \%$ of rice husk addition, and the lowest value of $17.5 \%$ was obtained from the pure alumina composition. The porosity gain intensified for the composition with $30 \%$ addition of rice husk and also when the particle size of the rice husk was increased, since the burning of the $\mathrm{RH}$ generated pores in the structure of the material. The compressive strength inversely followed the porosity, that is, the more porous composition studied, the lower its strength. This behavior was already expected [15]. However, it was noted that, for the composition RH $<65 \mu \mathrm{m}$ with $15 \%$ addition, the porosity and compressive strength were lower than for the addition of 5\%. This should be a result of the residual cristobalite in the composition of $15 \%$, as can be observed in the diffractogram of Fig. 4, since the cristobalite may have closed the pores, but as it is a fragile phase, it reduced the mechanical resistance [1]. For the composition with the addition of $30 \%$, it was observed a higher porosity with very low mechanical strength, therefore there was no equilibrium between the phases formed with mullite and an excess of cristobalite.

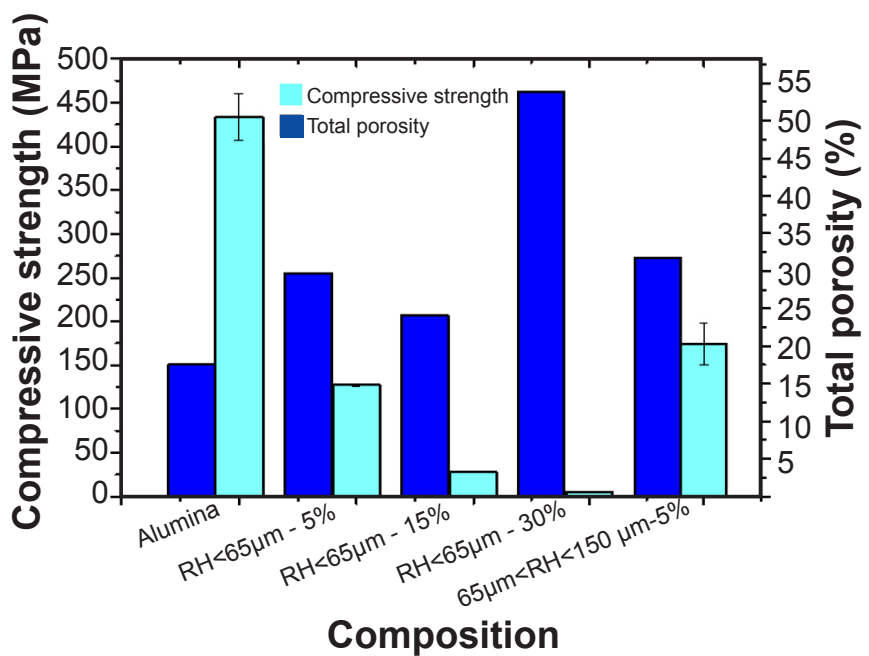

Figure 5: Total porosity and compressive strength of alumina sample and the samples produced with different quantities and size of rice husk.

Fig. 6 shows the monomodal frequency of the pore diameters present in the ceramics analyzed. It was observed that samples of porous alumina produced with different particles sizes and quantities of rice husk had a similar pore diameter frequency. In the compositions with rice husk, the pore frequency was concentrated in the size range of 0.18 to $0.19 \mu \mathrm{m}$, whereas the pure alumina composition presented lower frequency and also a narrower range of pore diameter values, when compared to other works and other ways of obtaining alumina ceramics $[1,2,5]$. The amount of rice husk used affected the number of pores that have a certain diameter. The composition $30 \% \mathrm{RH}<65 \mu$ m presented the

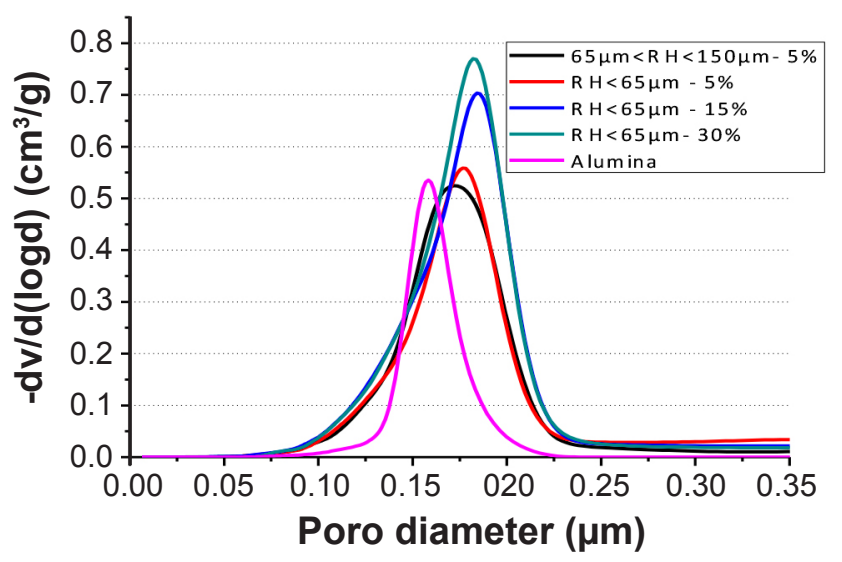

Figure 6: Frequency of pore diameters for each composition. 
highest number of pores with a diameter of $0.18 \mu \mathrm{m}$ and compositions with 5\% RH $<65 \mu \mathrm{m}$ and 5\% RH 65-150 $\mu \mathrm{m}$ presented the lowest number of pores with diameters close to $0.18 \mu \mathrm{m}$. Alumina showed the narrower pore size distribution and, as the amount of rice husk increased, the pore size distribution became wider.

Table I shows the results of sintered density (Q), porosity $(\mathrm{P})$, Young's modulus (E), modulus of rupture (MOR) and compressive strength of all compositions. It was observed that the addition of the rice husk generated the desired porosity in the compositions, thus, caused a decrease in the density and consequently of the mechanical properties. Comparing the compositions 5\% RH $<65 \mu \mathrm{m}$ and 5\% RH $65-150 \mu \mathrm{m}$ with similar porosity, it was observed that the composition with the highest particle size of rice husk (65 $\mu \mathrm{m}<\mathrm{RH}<150 \mu \mathrm{m})$ presented higher results of mechanical properties. This fact was related not only to porosity, but also to the mullite phase formed that contributed to this gain. A curious fact was observed for the composition 15\% RH $<65 \mu \mathrm{m}$, since it was expected a higher porosity and smaller values of mechanical resistance when compared to the composition 5\% RH $<65 \mu \mathrm{m}$, but that did not occur; instead, it was noticed a smaller porosity and a higher Young's modulus. During the three-point bending test, it was observed a deflection of the samples for this composition (15\% RH $<65 \mu \mathrm{m}$ ), justifying their higher modulus of elasticity. The decrease in the mechanical properties was associated with cristobalite, since there was not sufficient sintering time to react all the silica with the alumina to form mullite.

Fig. 7 shows micrographs of the fracture surface, after the 3-point bending test, of the studied compositions. From the analysis of the micrographs is possible to observe that with the addition of rice husk, the microstructure is porous, since in the first image, which shows the microstructure of the alumina, it presents a single-phase without considerable porosity. Thus, the addition of the rice husk caused the desired effect of generating pores in these ceramics. It was observed that with the addition of rice husk, the density decreased and the porosity increased, with evidence of large pores, such as those observed in the micrographs of the compositions with the addition of RH. This increase in porosity led to a decrease in the mechanical properties, but for the composition 5\% RH $65-150 \mu \mathrm{m}$, higher porosity value was obtained with a lower loss in mechanical properties. Thus, this composition was
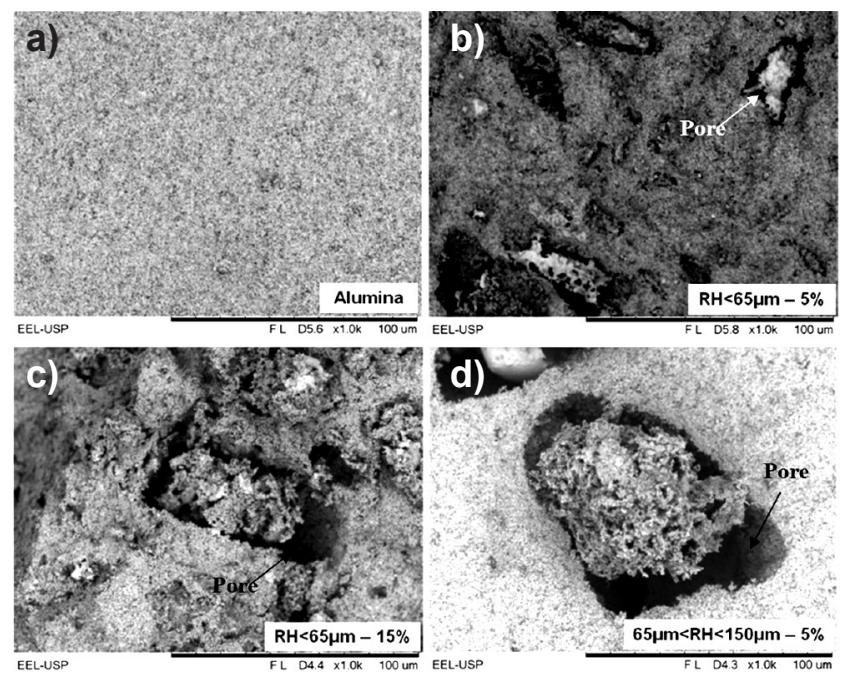

Figure 7: SEM images of fracture surface of the compositions with rice husk addition and pure alumina composition.

the one that presented the most attractive results in terms of porosity gain without large losses in mechanical strength. For the compositions with $\mathrm{RH}<65 \mu \mathrm{m}$, it was observed that the samples with $15 \%$ addition resulted in lower porosity than those with $5 \%$ addition. This may have occurred because of the presence of residual cristobalite that did not have sufficient time to react with alumina. Comparing the presented results with the those reported in [2], it was observed some similarity between the results of mechanical properties for a similar porosity value. However, it was seen that in the present study, using only $5 \%$ of rice husk, higher porosity was obtained [2]. Dele-Alofabi et al. [5] also obtained results of porosity for additions of 5\% of rice husk lower than that obtained in this work. Therefore, it was possible to obtain porous ceramics with good mechanical properties, feasible to be applied as insulating coatings for furnaces [21].

\section{CONCLUSIONS}

Rice husk (RH) can be used as a source of silica and pore forming agent in ceramic matrices. The ceramics with additions of 5 to $15 \mathrm{wt} \%$ of RH in two granulometry $(<65$ $\mu \mathrm{m}$ and $65-150 \mu \mathrm{m}$ ) presented a large number of pores with similar diameters. This was possibly the result of time and

Table I - Sintered density (@), total porosity (P), Young's modulus (E), modulus of rupture (MOR) and compressive strength of all compositions.

\begin{tabular}{cccccc}
\hline Composition & $\begin{array}{c}\mathrm{Q} \\
\left(\mathrm{g} / \mathrm{cm}^{3}\right)\end{array}$ & $\begin{array}{c}\mathrm{P} \\
(\%)\end{array}$ & $\begin{array}{c}\mathrm{E} \\
(\mathrm{GPa})\end{array}$ & $\begin{array}{c}\text { MOR } \\
(\mathrm{MPa})\end{array}$ & $\begin{array}{c}\text { Compressive } \\
\text { strength }(\mathrm{MPa})\end{array}$ \\
\hline Alumina & $3.06 \pm 0.12$ & 17.5 & $194 \pm 17$ & $157 \pm 33$ & $434 \pm 27$ \\
$5 \% \mathrm{RH}<65 \mu \mathrm{m}$ & $2.38 \pm 0.02$ & 29.7 & $74 \pm 2$ & $63 \pm 5$ & $127 \pm 1$ \\
$15 \% \mathrm{RH}<65 \mu \mathrm{m}$ & $1.93 \pm 0.02$ & 24.1 & $150 \pm 9$ & $18 \pm 2$ & $27.9 \pm 0.3$ \\
$30 \% \mathrm{RH}<65 \mu \mathrm{m}$ & $1.52 \pm 0.01$ & 53.9 & $-*$ & $-*$ & $4.3 \pm 0.4$ \\
$5 \% \mathrm{RH} 65-150 \mu \mathrm{m}$ & $2.70 \pm 0.07$ & 31.7 & $122 \pm 6$ & $85 \pm 11$ & $174 \pm 24$ \\
\hline
\end{tabular}

*- samples did not withstand the cutting stage. 
temperature used during the firing that allowed the atomic diffusion until those pores achieved the maximum diameter. Crystalline phases analysis showed the formation of mullite with the addition of rice husk. However, it was also observed in the compositions of 15 and $30 \%$ of rice husk additions that cristobalite was present, indicating that $1 \mathrm{~h}$ of sintering time at $1450{ }^{\circ} \mathrm{C}$ was not enough for all the silica from the rice husk to react with alumina and generate mullite. Porous ceramics with total porosity ranging from $24 \%$ to $54 \%$ were produced, and with the composition of 5\% RH $65-150 \mu \mathrm{m}$, a high porosity was obtained with a lower loss in mechanical properties.

\section{ACKNOWLEDGMENTS}

The authors would like to thank the research supporting agencies CNPq and FAPERJ (2017033116) for the master and post-doctorate granted scholarships, to the National Institute for Space Research (INPE) for the porosimetry analysis and São Paulo State University (UNESP) - School of Engineering of Guaratinguetá (FEG) for the flexural testing.

\section{REFERENCES}

[1] L.L. de Sousa, R. Salomão, V.L. Arantes, Ceram. Int. 43, 1 (2017) 1362.

[2] K. Mohanta, A. Kumar, O. Parkash, D. Kumar, J. Eur. Ceram. Soc. 34, 10 (2014) 2401.

[3] R. He, Z. Qu, X. Cheng, Ceram. Int. 42, 2 (2016) 2257.

[4] K. Prabhakaran, A. Melkeri, N.M. Gokhale, S.C. Sharma, Ceram. Int. 33, 1 (2007) 77.

[5] T.T. Dele-Afolabi, M.A. Azmah Hanim, M.
Norkhairrunnisa, S. Sobri, R. Calin, Ceram. Int. 43, 2 (2017) 1633.

[6] H.N. Yoshimura, A.L. Molisani, G.R. Siqueira, A.C. Camargo, N.E. Narita, P.F. Cesar, H. Goldenstein, Cerâmica 51 (2005) 239.

[7] J.A. Rodrigues, F.S. Ortega, A.E.M. Paiva, E.L.G. Villaboim, V.C. Pandolfelli, Cerâmica 50 (2004) 209.

[8] W.L. Vasconcelos, Cerâmica 43 (1997) 120.

[9] R.C.O. Romano, V.C. Pandolfelli, Cerâmica 52 (2006) 213.

[10] J. Liu, Y. Li, Y. Li, S. Sang, S. Li, Ceram. Int. 42, 7 (2016) 8221.

[11] V.P. Della, I. Kuhn, D. Hotza, Quím. Nova. 24 (2001) 778.

[12] R.R. Menezes, E. Fagury-Neto, M.C. Fernandes, P.M. Souto, R.H.G.A. Kiminami, Cerâmica 54 (2008) 245.

[13] V.P. Della, I. Kuhn, D. Hotza, Cerâm. Ind. 10 (2005) 2. [14] J.-J.F. Saceda, R.L. Leon, K. Rintramee, S. Prayoonpokarach, J. Wittayakun, Quím. Nova 34 (2011) 1394.

[15] J. Wang, J. Zhao, Ceram. Int. 43, 18 (2017) 16430.

[16] W. Guo, H. Lu, C. Feng, J. Rare Earth. 28, 4 (2010) 614.

[17] M.V.M Magliano, V.C. Pandolfelli, Cerâmica 56 (2010) 368.

[18] ASTM Int., C133-97, "Standard test methods for cold crushing strength and modulus of rupture of refractories" (2003).

[19] C.B. Carter, M.G. Norton, Ceramic materials: science and engineering, Springer, New York (2007) 298.

[20] G.B. Cintra, M.A.L. Braulio, L.R.M. Bittencourt, V.C. Pandolfelli, Cerâmica 56 (2010) 15.

[21] V.L. Arantes, L.L. de Sousa, R. Salomão, in Proc. $60^{\text {th }}$ Braz. Congr. Ceram., Águas Lindóia (2016) 1010.

(Rec. 28/09/2018, Rev. 14/11/2018, Ac. 20/11/2018) 